\title{
Arbuscular mycorrhizal fungi regulate flowering of hyacinths orientalis I. Anna marie
}

\author{
Miao-Miao Xie ${ }^{1,2}$, Qiang-Sheng $\mathrm{Wu}^{1,2,3 *}$ \\ ${ }^{1}$ College of Horticulture and Gardening, Yangtze University, Jingzhou, Hubei 434025, China, ${ }^{2}$ Institute of Root Biology, Yangtze University, \\ Jingzhou, Hubei 434025, China; ${ }^{3}$ Department of Chemistry, Faculty of Science, University of Hradec Kralove, Hradec Kralove 50003, Czech \\ Republic
}

\section{A B S T R A C T}

\begin{abstract}
Arbuscular mycorrhizal fungi (AMF) represent positive effects on growth performance, nutrient absorption and stressed tolerance of host plants, whereas it is not clear whether AMF can affect flowering traits of ornamental plants. In this work, Diversispora spurca, D. versiformis, and Funneliformis mosseae were applied to rhizosphere of potted hyacinth (Hyacinths orientalis L. Anna Marie) plants. After four months of mycorrhizal inoculation, root could be colonized by exogenous AMF species, varied from $38 \%$ to $49 \%$, whilst $F$. mosseae had the best mycorrhizal status. Out of these AMF species used, only $F$. mosseae-inoculated plants recorded greater raceme length and biomass production of single flowerlet, raceme, and flower stem. F. mosseae also induced the flowering earlier in 2 days and prolonged flowering time for 3 days. D. versiformis postponed 2 days for flowering. Mycorrhizal plants recorded considerably higher acetic acid (IAA) and zeatin riboside (ZR) levels in flowers, irrespective of AMF species. F. mosseae-inoculated plants had significantly higher methyl jasmonate (MeJA) concentrations in flowers than other AMF- or non-AMF-treated plants. These results thereby conclude that $F$. mosseae can be used to regulate flowering of $H$. orientalis $\mathrm{L}$. Anna Marie, including flowering earlier and prolonging flowering time, which is closely associated with IAA, ZR and MeJA levels in flowers.
\end{abstract}

Keywords: Auxin; Flowering earlier; Mycorrhiza; Ornamental plants; Zeatin riboside

\section{INTRODUCTION}

Arbuscular mycorrhizal fungi (AMF), a kind of soil inhabited microbes, can establish symbiotic association (namely, arbuscular mycorrhiza) with most of terrestrial plants (Bainard et al., 2011). The presence of arbuscular mycorrhiza shows lots of benefits in the host plants, including enhancement in quality and growth of crops, improvement in physical and chemical properties of soils, increment in survive rate of micropropagated plants, alleviation of magnesium deficiency and drought stress, and enhancement in disease and insect resistance of plants (Garmendia et al., 2004, 2005; Garmendia and Mangas, 2012; Zhang et al., 2015; Liu et al., 2016).

Hyacinth is native to the Mediterranean region and South Africa (Mabberley, 1997) and has 500 to 700 species, characterized by gorgeous flower color and a powerful bouquet. As a result, hyacinths extensively apply to parterre, flower mirror, garden, and cut-flower (Xie and Wu, 2017). Under the artificial vegetation of florescence, there is being a new highlight in regulating flowering time by means of temperature, light, culture mediums, and plant growth regulators (Hayama and Coupland, 2003; Nazari et al., 2011; Abdulrahman et al., 2012; Miyamoto et al., 2015). In floriculture, soil AMF contributes positive effects on flowering regulation of ornamental plants. As reported by Scagel $(2003,2004)$, inoculation with Funneliformis mosseae notably enhanced the number of flowers and prolonged lifetime of flowers in cut flower roses. Usha et al. (2005) observed that Glomus deserticola markedly resulted in ahead of time in flowering of grapevines. Asara et al. (2012) also found the increase in the size of flowers in snapdragon (Antirbinum majus cv. butterfly) plants after colonized by G. deserticola (Trappe and John). However, part studies also showed that AMF could make flowering time delayed (Saia et al., 2014) and had no effect on the number of flowers (Linderman and Davis, 2004).

\footnotetext{
${ }^{*}$ Corresponding author:

Qiang-Sheng Wu, College of Horticulture and Gardening, Yangtze University, Jingzhou, Hubei 434025, China, Institute of Root Biology, Yangtze University, Jingzhou, Hubei 434025, China; Department of Chemistry, Faculty of Science, University of Hradec Kralove, Hradec Kralove 50003, Czech Republic. E-mail: scott.wuqiangsh@163.com.
} 
Even so, the information about AMF roles on flowering of decorative plants is poorly known. Therefore, the objective of this work intended to evaluate the AMF influences on flowering time and raceme of hyacinth, in combination with the changes in endogenous hormones of flowers.

\section{MATERIALS AND METHODS}

\section{Experimental materials and plant set-up}

Three AM fungal species were selected as the fungal materials, which included Diversispora spurca, D. versiformis, and F. mosseae, respectively. These AMF species were provided by the Institute of Plant Nutrition and Resources, Beijing Academy of Agriculture and Forestry Sciences and further propagated by white clover under the condition of pots.

Hyacinths orientalis L. Anna Marie was selected as the plant material here. The seedballs $(16-17 \mathrm{~cm}$ diameter) of the hyacinth with were surface-disinfected by $75 \%$ of alcohol solution for $10 \mathrm{~min}$ and sown into pots $(16 \times 11 \times 13 \mathrm{~cm}$, top diameter $\times$ bottom diameter $\times$ height) on October 23, 2015, where $2 \mathrm{~kg}$ of autoclaved mixture with soils and sands $(3: 1, \mathrm{v} / \mathrm{v})$ were supplied. Approx. 1100 spores of AM fungus were mixed with the growth substrate of each pot. The same amount of autoclaved inoculants plus $2 \mathrm{~mL}$ inoculum filtrate ( $25 \mu \mathrm{m}$ filter) was supplied into pots as the non-AMF control.

The AMF- and non-AMF-inoculated plants were grown in a controlled environment, where photosynthetic photon flux density was $768 \mu \mathrm{mol} / \mathrm{m}^{2} / \mathrm{s}$, and day $/$ night temperature was $18 / 10^{\circ} \mathrm{C}$. To reduce the environmental effects, all of pots were weekly rotated the place.

\section{Experimental design}

The experiment was designed with four AMF treatments, accompanied with a completely randomized arrangement: Funneliformis mosseae, Diversispora spurca, Diversispora versiformis, and the non-AMF control. Each treatment replicated nine times in a total of 36 pots.

\section{Determinations of flower traits}

After 130 days of seedball planting, the hyacinth plants had more than $50 \%$ flowerlets bloomed, which is in full flowering stage. Raceme per plant was harvested, whose fresh weight and length were determined. In addition, fresh weight in single flowerlet and flower stem was also measured. The time in first-flowering (the first flowerlet bloomed), full-flowering ( $>50 \%$ flowerlets bloomed), and final-flowering (>95\% flowerlet bloomed) in raceme was recorded.

\section{Estimation of root AMF colonization}

Fresh root systems with 1 -cm long were stained by $0.05 \%$ $(\mathrm{w} / \mathrm{v})$ of trypan blue, as per the protocol described by
Phillips and Hayman (1970). Root AMF colonization (\%) $=$ mycorrhiza-colonized root lengths/total observed root lengths $\times 100$. Entry points were expressed as the number of entry points per $\mathrm{cm}$ root.

\section{Determinations of phytohormones levels in flowers}

The fresh flowerlets with $0.20 \mathrm{~g}$ were extracted with $4 \mathrm{~mL}$ of $80 \%$ methanol solutions containing $1 \mathrm{mM}$ 2,6-ditert-butyl-4-methylphenol at ice-bath, inoculated at $4^{\circ} \mathrm{C}$ for $4 \mathrm{~h}$, centrifuged at $4000 \mathrm{r} / \mathrm{min}$ for $10 \mathrm{~min}$, and isolated by an AccuBond C18 soild phase kit (Agilgent Technologies Inc., USA) (Chen et al., 2009). Afterwards, the enzyme-linked immune kits were used to measure the concentrations of acetic acid (IAA), total gibberellic acids (GAs), brassin (BR), zeatin riboside (ZR), methyl jasmonate (MeJA).

\section{Statistical analysis}

The collected data were analyzed by one-way variance (ANOVA) in the SAS software $(8.1 \mathrm{v})$. Duncan's multiple range test was used to compare significant difference between the treatments at 5\% level.

\section{RESULTS}

\section{Root mycorrhizal status}

The roots of $H$. orientalis L. Anna Marie were colonized by D. spurca, D. versiformis and F. mosseae, and the significantly higher root colonization and entry points ranked as F. mosseae $>$ D. spurca $>$ D. versiformis in the decreasing order (Fig. 1).

\section{Flower traits}

Treatments with AMF represented diverse effects on the fresh weights of single flowerlet, raceme, and flower stem, dependent on AMF species (Fig. 2; Fig. 3). Meanwhile, plants inoculated only with $F$. mosseae possessed significantly higher single flowerlet, raceme, and flower stem biomass production than those with other inoculated and uninoculated treatments.

Amongst the used AMF species, the hyacinth plant inoculated only with F. mosseae recorded considerably greater raceme length (Fig. 3; Fig. 4). D. versiformis and D. spurca exhibited no significant effect on raceme length, relative to non-AMF-inoculated treatment.

\section{Flowering time}

Compared with non-AMF plants, D. spurca-colonized plants showed longer days in the stage of final flowering, $D$. versiformis-colonized plants needed to have longer days to flower in first flowerlet, and F. mosseae-inoculated plants exhibited shorter days to flower in first flowerlet (Table 1). In addition, the daily number of blooming 


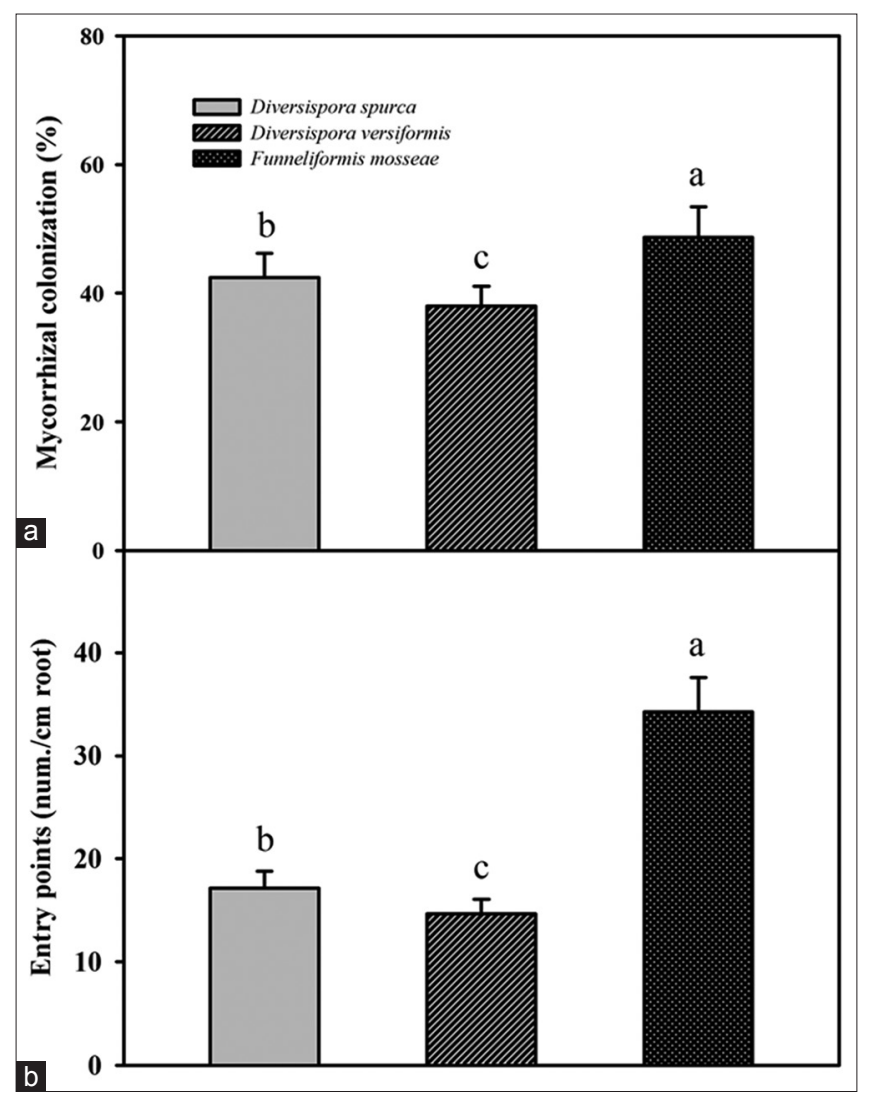

Fig 1. Root colonization (a) and entry points (b) in Hyacinths orientalis L. Anna Marie inoculated with Diversispora spurca, D. versiformis and Funneliformis mosseae. Data (means $\pm \mathrm{SD}, n=3$ ) followed by different letters above the bars showed significant differences $(P<0.05)$ between treatments.

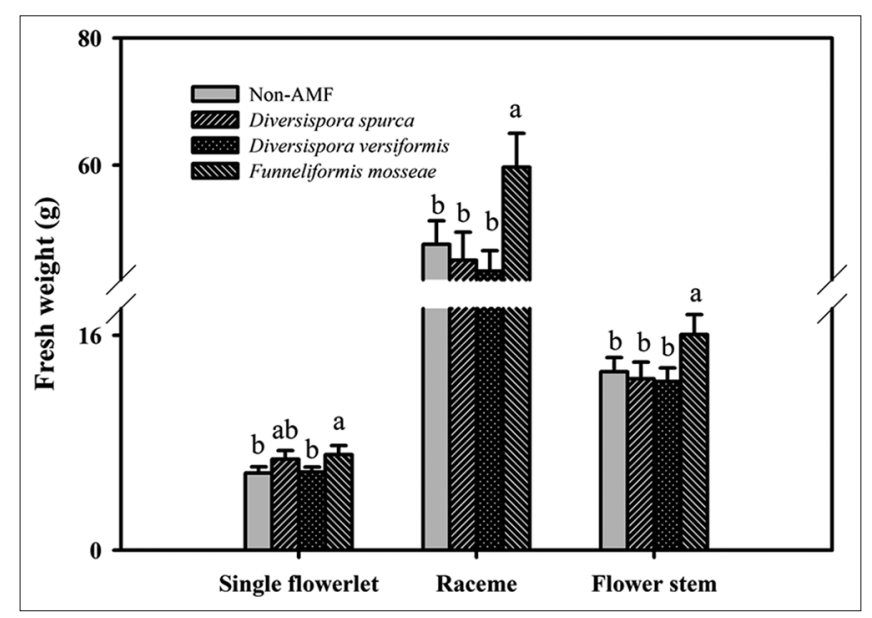

Fig 2. Effects of Diversispora spurca, D. versiformis, and Funneliformis mosseae on biomass of single flowerlet, raceme, and flower stem in Hyacinths orientalis L. Anna Marie. Data (means $\pm \mathrm{SD}, n=3$ ) followed by different letters above bars showed significant differences $(P<0.05)$ between treatments.

flowerlet was greater with $F$. mosseae inoculation while less with D. spurca and D. versiformis inoculation, compared with non-mycorrhizal inoculation in the whole flowering period.

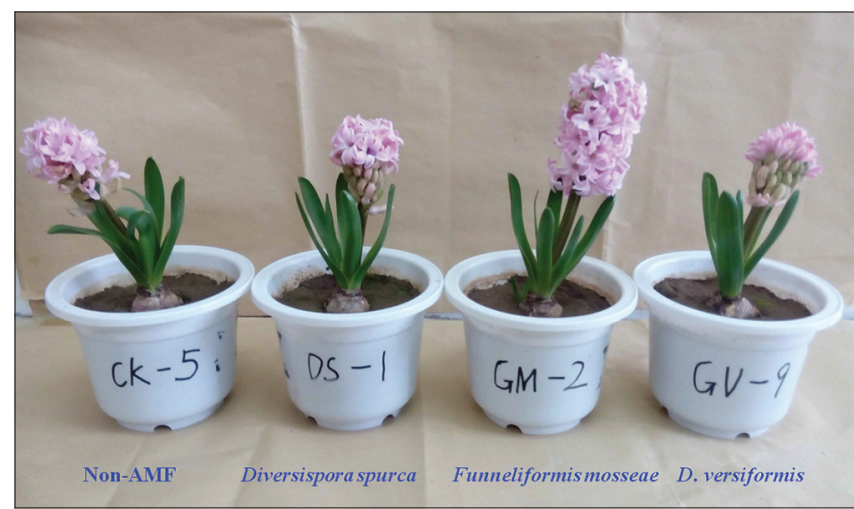

Fig 3. Flowering status of Hyacinths orientalis L. Anna Marie inoculated with Diversispora spurca, D. versiformis, and Funneliformis mosseae.

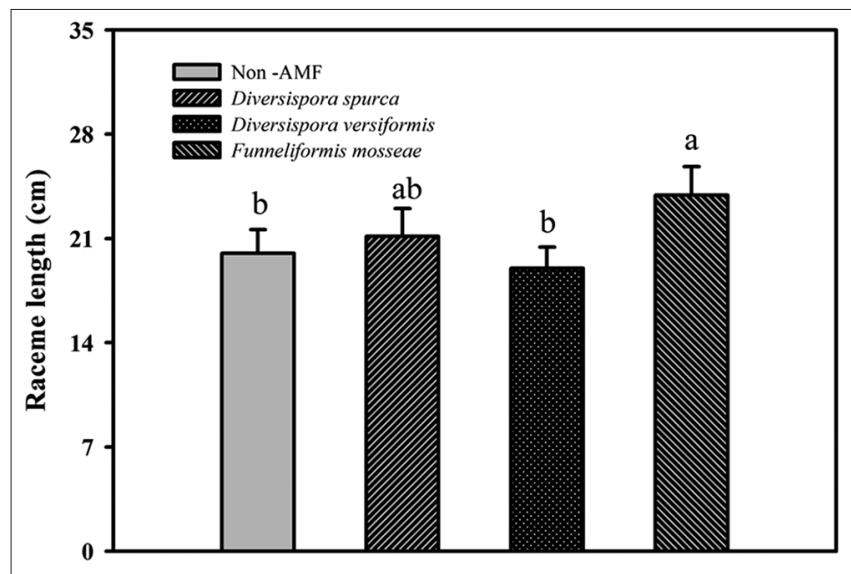

Fig 4. Effects of Diversispora spurca, D. versiformis, and Funneliformis mosseae on raceme length of flowers in Hyacinths orientalis L. Anna Marie. Data (means $\pm \mathrm{SD}, n=3$ ) followed by different letters above bars showed significant differences $(P<0.05)$ between treatments.

\section{Endogenous phytohormone concentrations in flow ers}

Compared with non-AMF treatment, F. mosseae, D. versiformis and $D$. spurca significantly increased the IAA concentration of flowers by $19.6 \%, 19.4 \%$ and $17.7 \%$, respectively (Fig. 5). Mycorrhizal plants colonized by F. mosseae, D. versiformis and D. spurca also represented $15.9 \%, 15.0 \%$, and $12.7 \%$ higher ZR concentration of flowers in comparison with non-mycorrhizal plants. Inoculated plants had similar GAs and MeJA concentrations than un-inoculated controls, regardless of AMF species used, except a significant higher MeJA level in F. mosseae-inoculated plants.

\section{DISCUSSION}

The present study indicated that inoculation with AMF exhibited different colonized status in roots and different effects on biomass production of flowers in $H$. orientalis L. Anna Marie. It is well known that AMF has a different capacity to colonize roots (Davoodian et al., 2012), dependent on the compatibility between AMF and host 
Table 1: The effects of Diversispora spurca, D. versiformis, and Funneliformis mosseae on flowering days of Hyacinths orientalis L. Anna Marie in full-bloom period

\begin{tabular}{lcccc} 
Treatments & First-flowering days & Full-flowering days & Final-flowering days & Flowering time \\
\hline Non-AMF & $125.9 \pm 3.1 \mathrm{bc}$ & $131.3 \pm 1.5 \mathrm{ab}$ & $148.0 \pm 2.3 \mathrm{~b}$ & $22.1 \pm 2.0 \mathrm{bc}$ \\
Diversispora spurca & $126.8 \pm 2.0 \mathrm{ab}$ & $132.2 \pm 0.9 \mathrm{a}$ & $150.3 \pm 0.5 \mathrm{a}$ & $23.5 \pm 0.6 \mathrm{~b}$ \\
D. versiformis & $128.4 \pm 2.9 \mathrm{a}$ & $132.5 \pm 0.3 \mathrm{a}$ & $149.8 \pm 1.0 \mathrm{ab}$ & $21.4 \pm 0.9 \mathrm{c}$ \\
Funneliformis mosseae & $123.6 \pm 2.9 \mathrm{c}$ & $130.2 \pm 1.1 \mathrm{~b}$ & $149.0 \pm 1.7 \mathrm{ab}$ & $25.4 \pm 0.7 \mathrm{a}$ \\
\hline
\end{tabular}

Date (means $\pm S D, n=6)$ followed by different letters indicated significant differences $(P<0.05)$ between treatments

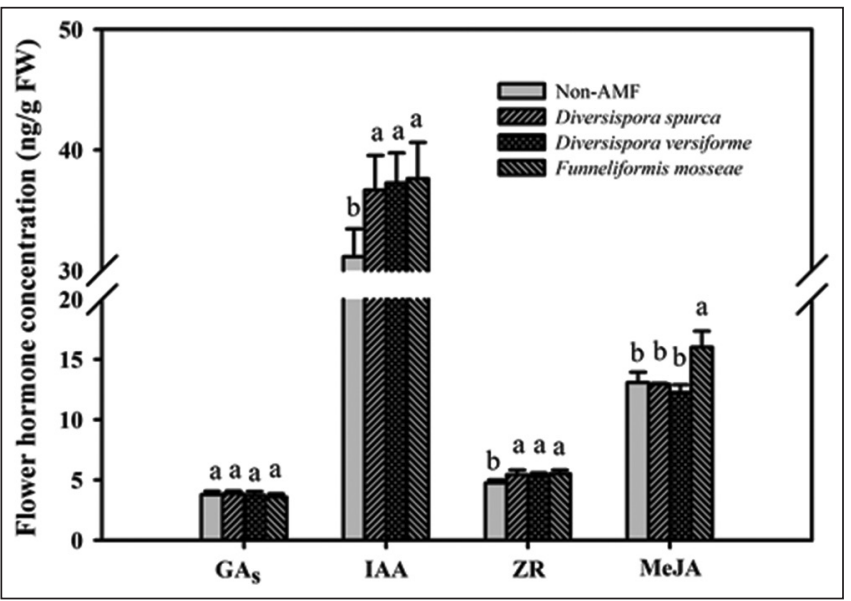

Fig 5. Effects of Diversispora spurca, $D$. versiformis, and Funneliformis mosseae on total gibberellic acids (GAs), acetic acid (IAA), zeatin riboside (ZR), and methyl jasmonate (MeJA) concentration of flowers in Hyacinths orientalis $\mathrm{L}$. Anna Marie. Data (means $\pm \mathrm{SD}, n=3$ ) followed by different letters above bars showed significant differences $(P<0.05)$ between treatments.

plants. In this work, only F. mosseae showed the highest root mycorrhizal colonization and entry points than the other AMF species, confirming that F. mosseae has the highefficient compatibility with the hyacinth plant species. It is consistent with previous studies in harlequin flower (Scagel, 2004). Future works need to consider the compatibility between F. mosseae and other hyacinth plant species.

In this work, AMF inoculation showed diverse effects on raceme length and biomass of single flowerlet, raceme, and flower stem in H. orientalis L. Anna Marie. Hereinto, F. mosseae represented a positive effect, while two Diversispora species manifested no significant effect. Earlier study by Asrar and Elhindi (2011) reported that inoculation with AMF increased the size of the flowers of marigold. Mycorrhizal inoculation markedly increased flower height of C. morifolium (Vaingankar and Rodrigues, 2012) or had no significant effect (Linderman and Davis, 2004). AMF also enhanced the number of flowers of snapdragon and Hypericum perforatum (Asrar et al., 2012; Lazzara et al., 2017) or had no effect on it (Mora, 1990). It concludes that AMF can potentially improve flower morphology, heavily depended on the compatibility of both AMF and host plants, which is still needed to be considered in future.
Studies in the past indicated that AMF increased flowering earliness (Gaur et al., 2000; Garmendia and Mangas, 2012; Bona et al., 2015), postponed flowering (Dubsky and Sramek, 2002; Nowak, 2004), or had no effect on flowering (Adholeya, 2005). Meanwhile, it has also been found that AMF was able to prolong flowering duration (Jin et al., 2015) or shorten it (Banla et al., 2015). In our work, inoculation with AMF had diverse effects on flowering duration, strongly dependent on AMF species. F. mosseae had the effect on flowering earliness, and D. versiformis had the effect on postponed flowering. Moreover, F. mosseae also prolonged flowering duration than non-AMF controls. As a result, F. mosseae can be used to regulate flowering of hyacinth plants, including flowering earlier and prolonging flower duration. Hence, users can select a suitable AM fungus to regulate the flowering earlier and/or prolonging in field.

Endogenous phytohormones are one of the important factors to regulate flowering of ornamental plants (Shamshiri, 2012). Perner et al. (2007) proposed that AMF colonization may directly or indirectly modulate hormone balance for affecting flower development and blooming. Auxin plays an important role to plant morphogenesis (Alabadí et al., 2009). In our study, AMF colonization strongly stimulated the significant increment of IAA concentration in flowers than non-AMF colonization, regardless of AMF species, which is similar to Torelli et al. (2000) in onion, Meixner et al. (2005) in soybean, and Liu et al. (2016) in trifoliate orange subjected to well-watered and drought stress. This implies that AMF may regulate flower development and blooming by means of accelerating IAA synthesis. Total GAs are a kind of important hormones to promote the formation of flowers (Zhang et al., 2014). However, in the present study, mycorrhizal inoculation did not significantly affect GAs level in flowers of hyacinth plants, which is in agreement with previous study in trifoliate orange under mycorrhization with F. mosseae (Liu et al., 2016). It seems that GAs did not participate in flower regulation by mycorrhization. Earlier works showed the increase in ZR level by F. mosseae in Citrus jambbiri Lush (Dixon et al., 1988) and in Poncirus trifoliata (Liu et al., 2016), which is confirmed by our study in hyacinth plants, irrespective of AMF species. In our work, F. mosseae, but not D. spurca and D. versiformis, significantly increased MeJA level of flowers in hyacinth. Since ZR improved respiration of flowers to expand 
petal and then induced blooming (Kobayasi and Atsuta, 2010), AMF-induced ZR increase might be the reason of AMF-stimulating flower development and blooming at an earlier stage, which depends on AMF species. In addition to phytohormones, plant nutrient status is an important factor in regulating flowering time and flower morphology in ornamental plants. As reported by Xie and Wu (2017), mycorrhizal inoculation induced greater concentrations of $\mathrm{N}, \mathrm{P}$, and $\mathrm{K}$ in flower, leaf, and roots of hyacinth plants. As a result, mycorrhiza-regulated flowering of ornamental plants is a complex issue by multiple physiological processes, which is still needed to be studied.

\section{CONCLUSION}

AMF species exhibited positive or no significant effect on flower biomass, raceme length and flowering time in H. orientalis L. Anna Marie. Hereinto, F. mosseae can be used to regulate flowering of the hyacinth plant, including flowering earlier and prolonging flower duration. The mycorrhizal effect is possibly due to the changes in IAA, $\mathrm{ZR}$ and MeJA levels in flowers by mycorrhization. Future works need to highlight mycorrhizal effects on flowering and transcriptional levels of relevant flowering genes in different hyacinth plants and flower fragrance constitutions in hyacinth plants.

\section{ACKNOWLEDGEMENTS}

This study was supported by the Plan in Scientific and Technological Innovation Team of Outstanding Young, Hubei Provincial Department of Education (T201604).

\section{A uthor contributions}

M-M. X and Q-S. W designed the study and took the data. M-M. X did the data analysis and wrote this paper. Q.-S. W supervised the research project and also corrected the paper.

\section{REFERENCES}

Abdulrahman, Y.A., S.F. Ali and H.S. Faizi. 2012. Effect of sucrose and ascorbic acid concentrations on vase life of snapdragon (Antirrhinum Majus L.) cut flowers. Int. J. Pure Appl. Sci. Technol. 13(2): 32-41.

Adholeya, A. 2005. Diverse response of five ornamental plant species to mixed indigenous and single isolate arbuscular mycorrhizal inocula in marginal soil amended with organic matter. J. Plant Nutr. 28(4): 707-723.

Alabadí, D., M.A. Blázquez, J. Carbonell, C. Ferrándiz, and M.A. Pérezamador. 2009. Instructive rolesfor hormones in plant development. Int. J. Dev. Biol. 53(8-10): 1597-1608.

Asrar, A.A., G.M. Abdel-Fattah and K.M. Elhindi. 2012. Improving growth, flower yield, and water relations of snapdragon (Antirhinum majus L.) plants grown under well-watered and water-stress conditions using arbuscular mycorrhizal fungi.
Photosynthetica 50(2): 305-316.

Asrar, A.W.A. and K.M. Elhindi. 2011. Alleviation of drought stress of marigold (Tagetes erecta) plants by using arbuscular mycorrhizal fungi. Saudi. J. Biol. Sci.18(18): 93-98.

Bainard, L.D., J.N. Klironomos and A.M. Gordon. 2011. Arbuscular mycorrhizal fungi intree-based intercropping systems: A review of their abundance and diversity. Pedobiologia 54(2): 57-61.

Banla, E.M., A. Banito and J.M. Sogbedji. 2015. Effects of arbuscular mycorrhizal fungi on the production of tomato in Togo. Int. J. Biol. Chem. Sci. 9(3): 1270-1276.

Bona, E., G. Lingua, P. Manassero, S. Cantamessa, F. Marsano, V. Todeschini, A. Copetta, G. D’Agostino, N. Massa, L. Avidano, E. Gamalero and G. Berta. 2015. AM fungi and PGP pseudomonads increase flowering, fruit production, and vitamin content in strawberry grown at low nitrogen and phosphorus levels. Mycorrhiza 25(3): 181-193.

Chen, Q., W.B. Qi, R.J. Reiter, W. Wei and B.M. Wang. 2009. Exogenously applied melatonin stimulates root growth and raises endogenous indoleacetic acid in roots of etiolated seedlings of Brassica juncea. J. Plant. Physiol. 166(3): 324-328.

Davoodian, N., J. Bosworth and N. Rajakaruna. 2012. Mycorrhizal colonization of Hypericum perforatum L. (Hypericaceae) from serpentine and granite outcrops on the Deer Isles, Maine. Northeast Nat. 19(3): 517-526.

Dixon, R.K., H.E. Garrett and G.S. Cox. 1988. Cytokinins in the root pressure exudate of Citrus jambhiri Lush. colonized by vesiculararbuscular mycorrhiza. Tree. Physiol. 4(1): 9-18.

Dubsky, M. and F. Sramek. 2002. Inoculation of cyclamen (Cyclamen persicum) and poinsettia (Euphorbia pulcherrima) with arbuscular mycorrhizal fungi and Trichoderma harzianum. Rostl. Vyroba. 48(2): 63-68.

Garmendia, I., N. Goicoechea and J. Aguirreolea. 2004. Effectiveness of three Glomus species in protecting pepper (Capsicum annuum L.) against verticillium wilt. Biol. Control. 31(3): 296-305.

Garmendia, I., N. Goicoechea and J. Aguirreolea. 2005. Moderate drought influences the effect of arbuscular mycorrhizal fungi as biocontrol agents against Verticillium-induced wilt in pepper. Mycorrhiza 15(5): 345-356.

Garmendia, I. and V.J. Mangas. 2012. Application of arbuscular mycorrhizal fungi on the production of cut flower roses under commercial-like conditions. Span J. Agric. Res. 10(1): 166-174.

Gaur, A., A. Gaur and A. Adholeya. 2000. Growth and flowering in Petunia hybrida, Callistephus chinensis and Impatiens balsamina inoculated with mixed AM inocula or chemical fertilizers in a soil of low P fertility. Sci. Hortic. 84(1-2): 151-162.

Hayama, R. and G. Coupland. 2003. Shedding light on the circadian clock and the photoperiodic control of flowering. Curr. Opin. Plant. Biol. 6(1): 13-19.

Jin, Z., J. Li and Y. Li. 2015. Interactive effects of arbuscular mycorrhizal fungi and copper stress on flowering phenology and reproduction of Elsholtzia splendens. PLoS ONE 10(12): e0145793.

Kobayasi, K. and Y. Atsuta. 2015. Sterility and poor pollination due to early flower opening induced by methyl jasmonate. Plant Prod. Sci. 13(1): 29-36.

Lazzara, H., M. Militello, A. Carrubba, E. Napoli and S. Saia. 2017. Arbuscular mycorrhizal fungi altered the hypericin, pseudohypericin, and hyperforin content in flowers of Hypericum perforatum grown under contrasting $P$ availability in a highly organic substrate. Mycorrhiza 27(4): 1-10.

Linderman, R.G. and E.A. Davis. 2004. Varied response of marigold (Tagetes spp.) genotypes to inoculation with different arbuscular 
mycorrhizal fungi. Sci. Hortic. 99(1): 67-78.

Liu, J., C. Guo, Z.L. Chen, J.D. He and Y.N. Zou. 2016. Mycorrhizal inoculation modulates root morphology and root phytohormone responses in trifoliate orange under drought stress. Emir. J. Food Agric. 28(4):251-256.

Mabberley, D.J. 1997. The Plant-Book: A portable dictionary of the vascular plants. $2^{\text {nd }}$ edition Cambridge University Press, New York, pp. 1-858.

Meixner, C., C. Meixner, J. Ludwigmüller, O. Miersch, P. Gresshoff, C. Staehelin and H. Vierheilig. 2005. Lack of mycorrhizal autoregulation and phytohormonal changes in the supernodulating soybean mutant nts1007. Planta 222(4): 709-715.

Miyamotoa, K., T. Kotakeb, A.J. Boncelac, M. Saniewskic and J. Uedad. 2015. Hormonal regulation of gummosis and composition of gums from bulbs of hyacinth (Hyacinthus orientalis). J. Plant. Physiol. 174(3): 1-4.

Mora, J.R.V. 1990. Effects of inoculation with pathogenic and beneficial microorganisms and ammonium or nitrate fertilization on easter lily growth. Ph.D. dissertation, Oregon State University, Oregon.

Nazari, F., H. Farahmand, M. Khosh-Khui and H. Salehi. 2011. Effects of coir as a component of potting media on growth, flowering and physiological characteristics of hyacinth (Hyacinthus orientalis $L$. cv. Sonbol-e-Irani). Int. J. Agric. Food. Sci. 1(2): 34-38.

Nowak, J. 2004. Effects of arbuscular mycorrhizal fungi and organic fertilization ongrowth, flowering, nutrient uptake, photosynthesis and transpiration of gera-nium (Pelargonium hortorum L.H. Bailey 'Tango Orange'). Symbiosis 37(1): 259-266.

Perner, H., D. Schwarz, C. Bruns, P. Mäder and E. George. 2007. Effect of arbuscular mycorrhizal colonization and two levels of compost supply on nutrient uptake and flowering of pelargonium plants. Mycorrhiza 17(5): 469-474.

Phillips, J.M. and D.S. Hayman. 1970. Improved procedures for clearing roots and staining parasitic and vesicular-arbuscular mycorrhizal fungi for rapid assessment of infection. Trans. Br.
Mycol. Soc. 55(1): 158-161.

Saia, S., G. Amato, A.S. Frenda, D. Giambalvo and P. Ruisi. 2014. Influence of arbuscular mycorrhizae on biomass production and nitrogen fixation of berseem clover plants subjected to water stress. PLoS ONE 9(3): e90738.

Scagel, C.F. 2003. Soil pasteurization and inoculation with Glomus intraradices alters flower production and bulb composition of Zephyranthes spp. J. Hortic. Sci. Biotech. 78(6): 798-812.

Scagel, C.F. 2004. Inoculation with vesicular-arbuscular mycorrhizal fungi and rhizobacteria alters nutrient allocation and flowering of harlequin flower. Horttechnology 14(1): 39-48.

Shamshiri, M.H., K. Usha and B. Singh. 2012. Growth and nutrient uptake responses of Kinnow to vesicular arbuscular mycorrhizae. Agronomy 2012(4): 689-693.

Torelli, A., A. Trotta, L. Acerbi, G. Arcidiacono, G. Berta and C. Branca. 2000. IAA and ZR content in leek (Allium porrum L.), as influenced by $P$ nutrition and arbuscular mycorrhizae, in relation to plant development. Plant Soil. 226(1): 29-35.

Usha, K., R. Mathew and B. Singh. 2005. Effect of three species of arbuscular mycorrhiza on bud sprout and ripening in grapevine (Vitis vinifera L.) cv. Perlette. Biol. Agric. Hortic. 23(1): 73-83.

Vaingankar, J.D. and B.F. Rodrigues. 2012. Screening for efficient AM (arbuscular mycorrhizal) fungal bioinoculants for two commercially important ornamental flowering plant species of Asteraceae. Biol. Agric. Hortic. 28(3): 167-176.

Xie, M.M. and Q.S. Wu. 2017. Mycorrhiza modulates morphology, color and duration of flowers in hyacinth. Biotechnol. 16(3):116-122.

Zhang, D., L. Ren, J. H. Yue, L. Wang, L. H. Zhuo and X.H. Shen. 2014. $\mathrm{GA}_{4}$ and IAA were involved in the morphogenesis and development of flowers in Agapanthus praecox ssp. orientalis. J. Plant. Physiol. 171 (11): 966-976.

Zhang, F., P. Du, C.X. Song and Q.S. Wu. 2015. Alleviation of magnesium deficiency by mycorrhiza in trifoliate orange: Changes in physiological activity. Emir. J. Food Agric. 27(10):763-769. 